\title{
Implantation of an esophageal squamous cell car- cinoma at the site of a percutaneous endoscopic gastrostomy
}

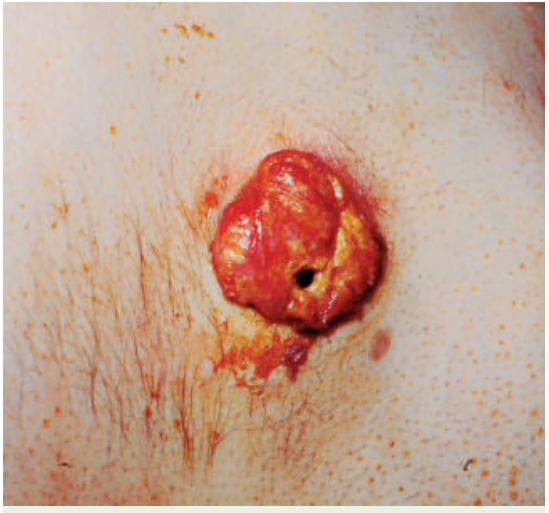

Fig. 1 Macroscopic aspect showing the skin alteration at the site of the PEG, which was regarded as granulation tissue.

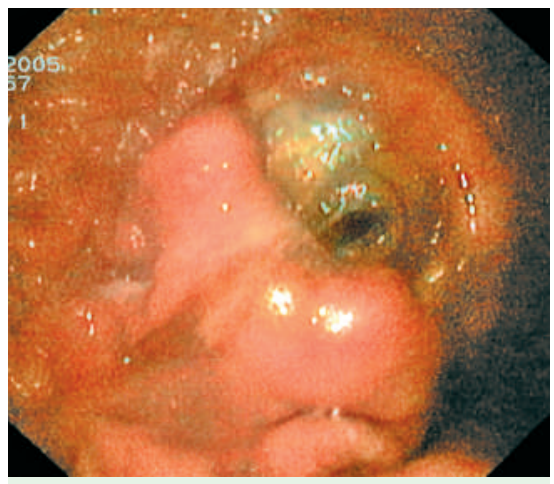

Fig. 2 Gastroscopic view of the tumor at the PEG site.

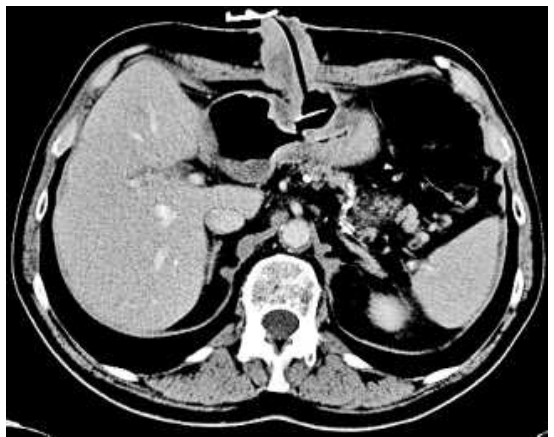

Fig. 3 Metastatic tumor implantation at the site of the PEG; the tumor mass extends from the gastric lumen to the skin.

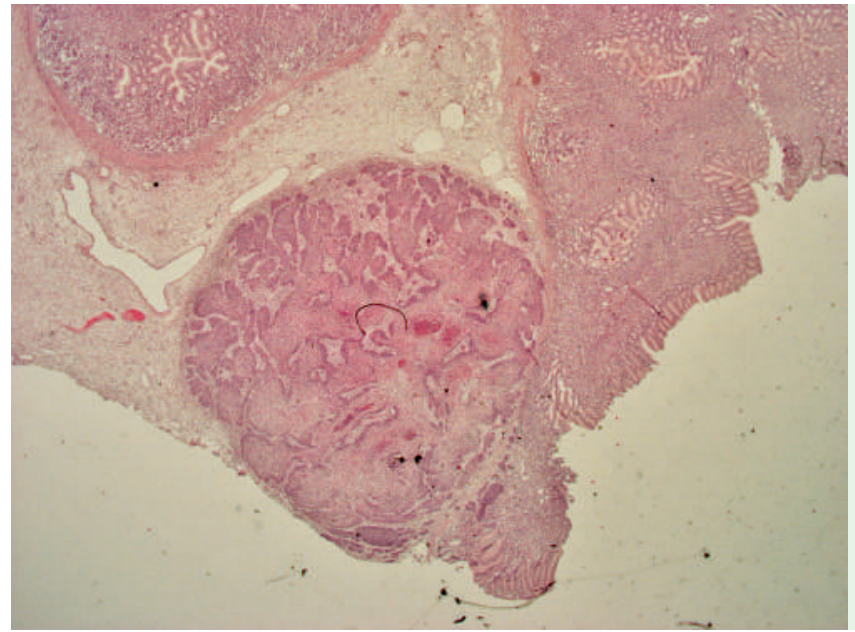

Fig. 4 Esophageal squamous cell carcinoma with distinctive lymphangiosis and hemangiosis carcinomatosa ( $\mathrm{H} \& \mathrm{E}$ staining)

A 54-year-old man presented with a stenosing, moderately differentiated squamous cell carcinoma (SCC) of the proximal esophagus. Tumor stage was cT34N1M0. The patient underwent radiochemotherapy with curative intent. A percutaneous endoscopic gastrostomy (PEG) was placed using the standard pullthrough method.

After 5 months the patient noticed a skin alteration at the site of the PEG, which was regarded as granulation tissue (৫ Fig. 1). In a routine gastroscopy 2 months later, an ulcer at the gastric site of the PEG was found ( $\bullet$ Fig. 2 ), and initially diagnosed as adenocarcinoma. Computed tomography demonstrated a tumor mass along the PEG-tube ( $\bullet$ Fig. 3). Additionally, a suspicious hypodense hepatic lesion was detected. Complete local esophageal tumor control was documented. At laparotomy, a frozen section of the liver lesion showed a poorly differentiated SCC. Therefore, palliative subtotal gastrectomy with en bloc resection of the abdominal wall was carried out (๑ Fig. 4).
Since the first description of PEG in 1980 [1], it has become a valuable method for nutritional support. The implantation of oropharyngeal or esophageal cancer at PEG stoma sites is a rare complication with an unknown incidence [2]. The average period of time from tube placement to metastatic spread is reported to be approximately 9 months (range 3-18 months) [3]. Length of survival following this complication is rarely reported, and varies between 2 and 28 months [4]. The mechanism of tumor spread to the PEG site is controversial. Hematogenous or lymphatic spread to a susceptible site, as well as - more likely - direct mechanical implantation at the time of the PEG placement are proposed [3-5]. To avoid mechanical tumor implantation, the contact of the PEG tube with the tumor should be minimized. In patients with bulky, stenosing tumors this can be achieved by using a sheath or overtube. Alternatively, radiologic or operative placements can be carried out.

Endoscopy_UCTN_Code_CPL_1AH_2AI 
K. Volkmer ${ }^{1}$, T. Meyer ${ }^{1}$, M. Sailer ${ }^{2}$, M. Fein ${ }^{1}$

1 Department of Surgery, University Hospital of Wuerzburg, Julius-MaximiliansUniversity Wuerzburg, Germany

2 Bethesda Hospital, Hamburg-Bergedorf, Germany

\section{References}

1 Gauderer MWL, Ponsky JL, Izant RJ. Gastrostomy without laparotomy: a percutaneous endoscopic technique. J Pediatr Surg 1980; 15: $872-875$

2 Maccabee D, Sheppard BC. Prevention of percutaneous endoscopic gastrostomy stoma metastases in patients with active oropharyngeal malignancy. Surg Endosc 2003 17: 1678

3 Thakore JN, Mustafa M, Suryaprasad S, Agrawal S. Percutaneous endoscopic gastrostomy associated gastric metastasis. J Clin Gastroenterol 2003; 37: 307 - 311

4 Ananth S, Amin M. Implantation of oral squamous cell carcinoma at the site of a percutaneous endoscopic gastrostomy: a case report. Br J Oral Maxillofac Surg 2002; 40: $125-130$

5 Peghini P, Guaouguaou N, Salcedo J, Al-Kawas $F$. Implantation metastasis after PEG: case report and review. Gastrointest Endosc 2000; 51 : 480-482
Bibliography

DOI 10.1055/s-2007-966793

Endoscopy 2007; 39: E240 - E241

(c) Georg Thieme Verlag KG Stuttgart · New York . ISSN 0013-726X

Corresponding author

\section{Fein, MD}

Department of Surgery

Zentrum Operative Medizin (ZOM)

Oberduerrbacher Strasse 6

D - 97080 Wuerzburg

Germany

Fax: +49-931-201-31049

Fein_M@chirurgie.uni-wuerzburg.de 